\title{
THE SUMMER MEETING IN CHICAGO
}

The forty-seventh Summer Meeting of the Society and the twentythird Colloquium were held at the University of Chicago, Chicago, Illinois, Tuesday to Saturday, September 2-6, 1941. The Mathematical Association of America met on Monday morning and afternoon, and jointly with the Society on Wednesday afternoon. The Institute of Mathematical Statistics held sessions Tuesday morning and afternoon and Wednesday afternoon. The Econometric Society met Tuesday, Wednesday and Thursday mornings and Tuesday afternoon.

The meeting was held in connection with the Fiftieth Anniversary Celebration of the University of Chicago, and on Tuesday morning Mr. Frederic Woodward, vice president emeritus of the University and director of the Celebration, gave a greeting and welcome to the mathematicians. As a part of the Fiftieth Anniversary Celebration, the University of Chicago collaborated with the Society in arranging a special program of lectures and conferences.

The number of papers presented at this meeting is the largest in the history of the Society and the attendance the second largest. Six hundred thirty-five persons registered including the following four hundred twenty-four members of the Society:

C. R. Adams, V. W. Adkisson, R. P. Agnew, A. A. Albert, G. E. Albert, C. B. Allendoerfer, Warren Ambrose, M. R. Anderson, T. W. Anderson, K. J. Arnold, Emil Artin, W. L. Ayres, H. M. Bacon, R. M. Ballard, J. D. Bankier, R. W. Barnard, I. A. Barnett, Walter Bartky, R. E. Basye, Harry Bateman, R. A. Beaumont, M. M. Beenken, A. A. Bennett, D. L. Bernstein, R. M. Besancon, E. E. Betz, H. R. Beveridge, S. F. Bibb, Garrett Birkhoff, G. D. Birkhoff, H. L. Black, D. H. Blackwell, H. F. Blichfeldt, G. A. Bliss, Henry Blumberg, L. M. Blumenthal, M. L. Boas, R. P. Boas, Salomon Bochner, D. G. Bourgin, J. W. Bower, M. G. Boyce, A. T. Brauer, Richard Brauer, H. E. Bray, R. W. Brink, Leonard Bristow, F. L. Brooks, H. E. Buchanan, C. E. Bures, F. J. H. Burkett, Herbert Busemann, Jewell H. Bushey, J. H. Bushey, W. H. Bussey, W. D. Cairns, J. W. Calkin, R. H. Cameron, C. C. Camp, E. J. Camp, H. H. Campaigne, A. D. Campbell, J. W. Campbell, W. B. Carver, C. R. Cassity, W. E. Cederberg, E. W. Chittenden, C. E. Clark, E. H. Clarke, M. D. Clement, A. B. Coble, C. J. Coe, L. M. Coffin, J. B. Coleman, Max Coral, J. J. Corliss, A. T. Craig, C. C. Craig, G. F. Cramer, H. B. Curry, H. B. Curtis, D. R. Curtiss, J. H. Curtiss, J. F. Daly, D. R. Davis, W. M. Davis, M. M. Day, J. J. DeCicco, L. J. Deck, F. F. Decker, C. H. Denbow, W. W. Denton, L. E. Dickson, Bernard Dimsdale, L. L. Dines, J. M. Dobbie, J. L. Doob, H. P. Doole, Arnold Dresden, D. M. Dribin, R. J. Duffin, Nelson Dunford, W. D. Duthie, P. S. Dwyer, J. J. Eachus, J. M. Earl, E. D. Eaves, M. C. Eide, Samuel Eilenberg, Churchill Eisenhart, M. L. Elveback, Benjamin Epstein, Paul Erdös, W. S. Erickson, H. J. Ettlinger, H. P. Evans, C. J. Everett, H. S. Everett, G. M. Ewing, F. A. Ficken, B. F. Finkel, C. H. Fischer, Edward Fleisher, L. R. Ford, R. M. Foster, R. H. Fox, Bernard Friedman, R. E. Fullerton, M. G. Gaba, E. R. Garbe, B. H. Gere, B. C. Getchell, K. S. Ghent, J. H. Giese, J. W. Givens, A. M. Gleason, H. H. Gold- 
stine, Michael Golomb, Cornelius Gouwens, C. H. Graves, L. M. Graves, W. L. Graves, F. L. Griffin, V. G. Grove, P. E. Guenther, P. R. Halmos, R. W. Hamming, E. H. Hanson, O. G. Harrold, W. L. Hart, M. L. Hartung, J. O. Hassler, Camilla Hayden, N. A. Haynes, K. E. Hazard, E. R. Hedrick, M. H. Heins, E. D. Hellinger, M. J. Herzberger, Fritz Herzog, A. D. Hestenes, M. R. Hestenes, J. F. Heyda, J. S. Hickman, T. H. Hildebrandt, F. C. Hinds, J. J. L. Hinrichsen, G. P. Hochschild, F. E. Hohn, D. L. Holl, M. P. Hollcroft, T. R. Hollcroft, A. S. Householder, E. M. Hove, E. M. Hull, M. G. Humphreys, E. V. Huntington, D. H. Hyers, M. H. Ingraham, Dunham Jackson, R. L. Jackson, Nathan Jacobson, R. D. James, R. L. Jeffery, E. D. Jenkins, L. L. Johnson, M. M. Johnson, F. B. Jones, H. A. Jordan, Mark Kac, Shizuo Kakutani, G. K. Kalisch, Wilfred Kaplan, Irving Kaplansky, William Karush, D. E. Kearney, I. F. Keeler, J. L. Kelley, Claribel Kendall, J. F. Kenney, J. R. F. Kent, R. B. Kershner, P. W. Ketchum, J. M. Kinney, Fred Kiokemeister, C. J. Kirchen, J. R. Kline, L. A. Knowler, E. R. Kolchin, Horace Komm, C. F. Kossack, W. C. Krathwohl, M. E. Ladue, W. D. Lambert, O. E. Lancaster, E. P. Lane, R. E. Lane, R. E. Langer, C. G. Latimer, D. H. Leavens, Solomon Lefschetz, R. A. Leibler, Walter Leighton, B. A. Lengyel, C. A. Lester, P. E. Lewis, C. B. Lindquist, Marie Litzinger, Charles Loewner, M. I. Logsdon, L. A. Lorch, R. G. Lubben, C. I. Lubin, N. H. McCoy, E. A. McDougle, A. W. McGaughey, J. V. McKelvey, M. M. McKelvey, Brockway McMillan, E. J. McShane, Saunders MacLane, H. M. MacNeille, H. F. MacNeish, W. G. Madow, J. D. Mancill, Szolem Mandelbrojt, Morris Marden, C. W. Mathews, J. R. Mayor, A. E. Meder, Kari Menger, Herman Meyer, H. L. Meyer, D. D. Miller, E. W. Miller, W. L. Miser, M. G. Moore, R. L. Moore, T. W. Moore, W. L. Moore, C. W. Moran, Vladimir Morkovin, Richard Morris, Marston Morse, E. J. Moulton, D. C. Murdoch, F. H. Murray, S. B. Myers, J. P. Nash, A. L. Nelson, Albert Neuhaus, John von Neumann, C. V. Newsom, K. L. Nielsen, Ivan Niven, E. A. Nordhaus, E. B. Ogden, Rufus Oldenburger, E. G. Olds, J. M. H. Olmsted, E. J. Olson, Isaac Opatowski, Oystein Ore, F. W. Owens, H. B. Owens, J. C. Oxtoby, Gordon Pall, T. P. Palmer, R. S. Park, R. S. Pate, J. F. Paydon, C. K. Payne, A. M. Pegram, I. E. Perlin, Sam Perlis, J. W. Peters, O. J. Peterson, H. R. Phalen, R. S. Phillips, C. G. Phipps, T. A. Pierce, Everett Pitcher, George Polya, Hillel Poritsky, J. E. Powell, G. B. Price, W. T. Puckett, H. A. Rademacher, Tibor Rad6, W. C. Randels, R. B. Rasmusen, Maxwell Reade, Francis Regàn, P. V. Reichelderfer, W. T. Reid, Haim Reingold, Eric Reissner, C. E. Rickart, J. F. Ritt, C. V. Robinson, S. L. Robinson, V. N. Robinson, W. H. Roever, C. F. Roos, J. B. Rosenbach, R. A. Rosenbaum, Arthur Rosenthal, A. E. Ross, R. G. Sanger, Max Sasuly, A. C. Schaeffer, Henry Scheffé, M. A. Scheier, Peter Scherk, O. F. G. Schilling, Abraham Schwartz, H. M. Schwartz, G. E. Schweigert, I. E. Segal, M. E. Shanks, J. W. Sheedy, Seymour Sherman, C. G. Shover, D. R. Shreve, Harry Siller, H. A. Simmons, M. E. Sinclair, M. M. Slotnick, M. F. Smiley, A. H. Smith, E. R. Smith, F. C. Smith, H. L. Smith, R. G. Smith, Virgil Snyder, W. S. Snyder, R. H. Sorgenfrey, T. H. Southard, V. E. Spencer, A. A. Stafford, G. W. Starcher, M. E. Stark, N. E. Steenrod, B. M. Stewart, M. H. Stone, E. C. Stopher, E. B. Stouffer, W. J. Strange, Otto Szász, Gabor Szegö, A. H. Taub, M. E. Taylor, W. C. Taylor, J. M. Thompson, R. M. Thrall, W. J. Thron, L. W. Tordella, W. J. Trjitzinsky, P. L. Trump, A. W. Tucker, J. W. Tukey, A. E. Turner, S. M. Ulam, E. H. Umberger, Henry Van Engen, J. I. Vass, W. A. Vezeau, R. W. Wagner, Abraham Wald, R. J. Walker, Henry Wallman, R. M. Walter, T. O. Walton, J. H. Weaver, M. S. Webster, J. V. Wehausen, M. J. Weiss, B. A. Welch, C. P. Wells, E. T. Welmers, I. L. Wente, M. E. Wescott, F. J. Weyl, Hermann Weyl, 
G. W. Whitehead, A. L. Whiteman, E. A. Whitman, P. M. Whitman, W. F. Whitmore, G. T. Whyburn, D. V. Widder, Norbert Wiener, L. R. Wilcox, R. L. Wilder, S. S. Wilks, E. W. Wilson, František Wolf, F. E. Wood, E. R. Worthington, C. H. Yeaton, J. W. T. Youngs, Oscar Zariski, J. W. Zimmer, Antoni Zygmund.

The Colloquium Lectures on the subject Mathematical relations and structures were given by Professor Oystein Ore of Yale University Wednesday, Thursday and Friday mornings. The presiding officers were Professors A. A. Albert, C. G. Latimer, and Emil Artin, respectively.

The sixteenth Josiah Willard Gibbs Lecture was given by Professor Sewall Wright of the University of Chicago on Wednesday evening. His title was Statistical genetics and evolution. President Marston Morse presided at this lecture.

Four general lectures were given under the composite title Trends in research. These were: Abstracts spaces by Professor M. H. Stone, Tuesday morning; Topology by Professor Solomon Lefschetz, Tuesday afternoon; The calculus of variations by Professor G. A. Bliss, Wednesday afternoon; and The analytic theory of numbers by Professor H. A. Rademacher, Friday afternoon. The presiding officers for these lectures were, in order, President Marston Morse, and Professors R. L. Wilder, R. W. Brink, and L. E. Dickson.

To present and discuss the latest developments in the fields of Algebra and the Theory of Integration, Conferences were held in these two subjects. These met simultaneously on Wednesday, Thursday and Saturday mornings. In the Conference on Algebra the speakers with their subjects were: Professor Garrett Birkhoff, Lattice-ordered abelian groups; Professor John von Neumann, Complete lattice abelian groups; Professor N. H. McCoy, Some aspects of the theory of matrices over a ring; Professor Nathan Jacobson, Lie algebras; Professor J. F. Ritt, Differential polynomials; Professor Oscar Zariski, Some recent results in the arithmetical theory of algebraic varieties; and Dr. O. F. G. Schilling, A Hilbert series theory for general algebraic extensions. The presiding officers of the Conference on Algebra were, in order, Professors A. A. Albert, Richard Brauer, and Hermann Weyl. In the Conference on the Theory of Integration the lectures were: Professor Salomon Bochner, Integration and partial ordering; Professor G. B. Price, Integration and convex operators; Professor T. H. Hildebrandt, The general integrals of E. H. Moore; Professor R. L. Jeffery, Some recent advances in the theory of non-absolutely convergent integrals; Professor Norbert Wiener, Measure in statistical mechanics; Professor Garrett Birkhoff, Product integrals; and Professor Nelson Dunford, Applications of the theory of integration to the study of linear operators. The 
presiding officers for the three sessions of the Conference on the Theory of Integration were Professors L. M. Graves, John von Neumann, and E. J. McShane.

Thirteen sectional sessions for the reading of short papers were held as follows: Mathematical Statistics (joint session with the Institute of Mathematical Statistics and Econometric Society), Tuesday morning; Analysis, Tuesday morning, Tuesday afternoon (two sections), Friday morning, Friday afternoon; Geometry, Tuesday morning; Topology and the Theory of Sets, Tuesday morning; Algebra, Tuesday afternoon, Friday afternoon; Algebra and the Theory of Numbers, Friday morning; Topology, Friday morning; Applied Mathematics, Friday afternoon. The presiding officers for these sectional sessions were, in order, Professors A. T. Craig, D. R. Curtiss, Dunham Jackson, Salomon Bochner, C. R. Adams, T. H. Hildebrandt, Virgil Snyder, J. W. Tukey, A. A. Bennett, Saunders MacLane, M. H. Ingraham, Solomon Lefschetz, and Norbert Wiener.

Headquarters for the meeting were in Judson Court. The dormitories of the University of Chicago were available to the members of the four mathematical organizations and their guests. The general lectures and the Gibbs Lecture were held in Kent Chemical Laboratory. All other sessions met in Eckhart Hall and the adjoining Ryerson Physical Laboratory.

On Monday evening the members of the Department of Mathematics of the University of Chicago gave an informal reception in Burton Court Lounge. Tea was served in Eckhart Hall on Tuesday and Wednesday afternoons by the ladies of the Department. There was a bridge tournament on Tuesday evening. A luncheon and fashion show were held. at Marshall Field and Company on Friday, and Friday evening a visit was made to Station WGN. Thursday afternoon was left free for recreation.

On Thursday evening there was a brief reception with officers of the four organizations receiving. This was followed by the joint dinner in Hutchinson Commons with an attendance of three hundred fortyone. President Marston Morse presided at the dinner. Professor Arnold Dresden spoke of the founding and early days of mathematics at the University of Chicago and particularly of the triumvirate Moore-Bolza-Maschke. At the close of his address he introduced the following resolution of greeting to Professor Oskar Bolza, the sole surviving member of this trio, which was adopted by a unanimous vote:

A large group of members of the American Mathematical Society and their guests, meeting in Chicago to take part in the Celebra- 
tion of the Fiftieth Anniversary of the Founding of the University of Chicago, send you their most affectionate greetings, mindful of the great contribution you have made to the development of mathematics in America and to its growth at the University of Chicago.

Professor Dresden was followed by Professor S. S. Wilks, who told of the history and purpose of the Institute of Mathematical Statistics and the Econometric Society, Professor D. R. Curtiss, who spoke of student days in Paris and the French professors of this era, and Professor G. A. Bliss, who read an announcement of the National Science Fund.

At the close of the dinner a resolution, introduced by Professor F. L. Griffin, extending felicitations to the University of Chicago upon its semicentennial and thanking it for the privilege of meeting as a part of the Celebration and expressing thanks to the Department of Mathematics for its fine arrangements and gracious hospitality, was adopted by a unanimous rising vote.

There were two meetings of the Council, one being a joint session with the Board of Governors of the Mathematical Association of America. This joint session to hear the report of the War Preparedness Committee was held at 4:30 P.M. in Eckhart Hall on Monday. This report appears elsewhere in this issue of the Bulletin. The other meeting of the Council was held at 8:15 P.M. on Tuesday in Judson Court Library.

The Secretary announced the election of the following twenty-nine persons to membership in the Society:

Dr. Fred Assadourian, New York University;

Dr. Herman Russell Branson, Dillard University, New Orleans, La.;

Dr. George William Brown, R. H. Macy and Company, New York, N. Y.;

Mr. George Eaddie Bulloch, New Jersey Bell Telephone Company, Newark, N. J.; Professor Elías Alfredo de Cesare, University of La Plata;

Dr. Myron Abraham Coler, Paragon Paint and Varnish Corporation, Long Island City, N. Y.;

Mr. Alexander Robert Craw, University of Notre Dame;

Dr. Joseph Francis Daly, Catholic University of America;

Professor Max Wilhelm Dehn, University of Idaho;

Mr. Jacques Dutka, Bronx, New York, N. Y.;

Mr. E. LaVerne Eagle, Dayton Y.M.C.A. College, Dayton, Ohio;

Professor Laurence Hadley, Purdue University;

Professor Louise Stokes Hunter, Virginia State College;

Professor Alfred Edward Johns, McMaster University, Hamilton, Ontario, Canada;

Mr. Seymour Matthew Kwerel, Columbia University;

Mr. Thorstein Larsen, Consolidated Edison Company, Brooklyn, N. Y.;

Dr. Charles Loewner, University of Louisville; 
Dr. Robert Sewell Pate, University of Illinois;

Mr. Murray Harold Protter, Brown University;

Professor Frank Atkinson Rickey, Louisiana State University;

Professor Mario O. González Rodríguez, University of Havana;

Dr. Leonard Jimmie Savage, Institute for Advanced Study;

Dr. William John Schart, Ohio State University;

Dr. Joseph A. Sharpe, Stanolind Oil and Gas Company, Tulsa, Okla.;

Dr. Ronald William Shephard, University of California;

Mr. William Henry Smith, Jr., Washington, D. C.;

Mr. Jonathan Dean Swift, California Institute of Technology;

Dr. Leopoldo Toralballa, Government Service Insurance System, Manila, Philippine Islands;

Dr. František Wolf, Macalester College, St. Paul, Minn.

It was reported that President Marston Morse will represent the Society at the One Hundred and Seventy-fifth Anniversary of the Founding of Rutgers University on October 9, 10, and 11, 1941. The following appointment by President Morse was also reported: as a subcommittee of the War Preparedness Committee, to be known as the Committee on Supply and Demand for Mathematicians, Professors T. Y. Thomas (chairman), Harry Bateman, E. T. Bell, G. C. Evans, and W. M. Whyburn.

Reports were sent in August to the Carnegie Corporation and Rockefeller Foundation regarding their grants to Mathematical Reviews.

The Secretary reported that copies of the recent report entitled Industrial Mathematics by Dr. T. C. Fry were distributed in August to members of the Society who are not members of the Mathematical Association of America.

Certain invitations to give hour addresses were announced: Professor G. B. Price for the November 1941 meeting in Manhattan, Kansas; Professors L. V. Bewley, I. S. Sokolnikoff and Oscar Zariski for the 1941 Annual Meeting at Lehigh University; Professor Norman Levinson for the February 1942 meeting in New York; Professor L. M. Blumenthal for the April 1942 meeting in Chicago; and Professor W. L. Ayres for the 1942 Summer Meeting at Cornell University.

On recommendation of the Committee on Places of Meetings (Professor A. B. Coble, chairman), the eastern spring meeting of 1942 was set at New York City, April 3-4. Times and places of meetings during 1942 were also set as follows: in New York City on February 28; in Berkeley, California on April 11; in Chicago on April 17-18; at Cornell University on September 8-11; in New York City on October 31; at the University of Notre Dame on November 27-28.

The seventeenth Josiah Willard Gibbs Lecture is to be given by 
Professor John von Neumann at the Annual Meeting of 1942 in New York City.

Dean L. P. Eisenhart and Dean R. G. D. Richardson were appointed representatives on the Council of the American Association for the Advancement of Science for 1942 and Professor M. H. Stone was appointed representative on the National Research Council for a period of three years beginning July 1942 .

The committee on the proposed new series of monographs, Mathematical Surveys (Professor J. L. Walsh, chairman), was empowered to proceed with the proposal presented by the Williams and Wilkins Company. In accordance with this proposal, the Company has agreed to publish at least two monographs, without commitment by the Society or the Company as to continuation. This committee was also empowered to appoint a temporary editorial board to act in connection with arrangements for the two monographs.

Professor G. B. Price reported for the Committee on Circulation for Mathematical Reviews that the total mailing list had increased from 1,222 on July 1,1940 to 1,369 on July 1, 1941. He also stated that new subscriptions are continuing to arrive from China, Japan, Russia, England, et cetera, thus emphasizing the truly international character of this journal.

A committee consisting of Professors M. H. Ingraham (chairman), L. M. Graves, and J. W. Tukey was appointed to consider the question of dues for persons drafted or enlisted for military service.

The Council voted to recommend to the Society that Section 9, Article VII of the By-Laws be amended so that no new life members will be accepted. Action will be taken on this proposal at the October meeting in New York City.

Titles and cross references to the abstracts of the papers read at this meeting follow below. Papers numbered 1 to 6 were read before the section for Mathematical Statistics, papers 7 to 12 before the section for Analysis Tuesday morning, papers 13 to 19 before the section for Geometry, papers 20 to 24 before the section for Topology and the Theory of Sets, papers 25 to 28 before the first section for Analysis Tuesday afternoon, papers 29 to 33 before the section for Algebra Tuesday afternoon, papers 34 to 38 before the second section for Analysis Tuesday afternoon, papers 39 to 45 before the section for Analysis Friday morning, papers 46 to 51 before the section for Algebra and the Theory of Numbers, papers 52 to 59 before the section for Topology, papers 60 to 66 before the section for Analysis Friday afternoon, papers 67 to 72 before the section for Algebra Friday afternoon, and papers 73 to 76 before the section for Applied 
Mathematics. Papers 77 to 141 , whose abstract numbers are followed by the letter $t$, were read by title. Paper number 9 was read by Professor Schaeffer, 10 by Dr. Bankier, 11 by Mr. Thron, 29 by Dr. Pate, 40 by Dr. Duffin, 58 by Professor Eilenberg, 60 by Dr. Kac, 61 by Dr. Halmos, and 62 by Professor Kakutani. Professor Burr was introduced by Professor W. L. Ayres, Dr. Mood by Professor E. G. Olds, Mr. Allen by Dr. P. E. Lewis, Mr. Young by Professor R. L. Moore, Professor Dehn by Professor Oswald Veblen, Dr. Weinstein by Dr. H. E. Robbins, and Dr. Nicholson by Professor S. E. Warschawski.

1. J. B. Coleman: A geometric derivation of Fisher's z-transformation. (Abstract 47-9-433.)

2. Abraham Wald: Large sample distribution of the likelihood ratio. (Abstract 47-11-486.)

3. I. W. Burr: Cumulative frequency functions. (Abstract 47-9-432.)

4. K. J. Arnold: On spherical probability distributions. (Abstract 47-9-431.)

5. A. M. Mood: On the asymptotic distribution of medians of samples from a multivariate population. (Abstract 47-9-436.)

6. J. F. Daly: A problem in estimation. (Abstract 47-11-483.)

7. L. R. Ford: The proper fractions. (Abstract 47-9-379.)

8. Otto Szász: Some new summability methods with applications. (Abstract 47-9-404.)

9. R. J. Duffin and A. C. Schaeffer: Power series with bounded coefficients. (Abstract 47-9-376.)

10. J. D. Bankier and Walter Leighton: Arithmetic continued fractions. (Abstract 47-9-366.)

11. Walter Leighton and W. J. Thron: Convergence criteria for continued fractions. (Abstract 47-7-308.)

12. J. F. Paydon: Convergence regions and value regions for continued fractions. Preliminary report. (Abstract 47-11-473.)

13. Abraham Schwartz: $A$ consequence of the Ricci equations for riemannian manifolds. (Abstract 47-9-426.)

14. T. R. Hollcroft: Types of distinct double points of primals. (Abstract 47-9-423.)

15. V. N. Robinson: A transformation between osculating curves of a rational normal curve in an odd dimensional space. (Abstract 47-7-323.)

16. J. J. DeCicco: Geometric characterization of functions of $n$ complex variables. (Abstract 47-9-420.)

17. F. E. Hohn: On Cartan's projective involutes. (Abstract 47-9422.) 
18. J. H. Giese: Conformally flat hypersurfaces of spaces of constant curvature. (Abstract 47-9-421.)

19. E. F. Allen: On a triangle inscribed in a rectangular hyperbola. (Abstract 47-9-417.)

20. R. G. Lubben: Decompositions of point sets and of portions of spaces. (Abstract 47-9-448.)

21. Horace Komm: Partial orders in euclidean spaces. (Abstract 479-446.)

22. S. M. Ulam: Theory of the operation of products of sets. I. Preliminary report. (Abstract 47-9-406.)

23. F. A. Ficken: Closure-mappings of partially ordered sets. Preliminary report. (Abstract 47-9-441.)

24. Henry Blumberg: A reconsideration of the paradoxes in the theory of sets. (Abstract 47-9-429.)

25. R. H. Cameron: Quadratic convolution equations. (Abstract 479-370.)

26. R. E. Langer: $A$ theory for ordinary linear differential boundary problems of highly irregular type. (Abstract 47-9-391.)

27. I. E. Perlin: A calculus of variations problem with end points as functions of the curve. Preliminary report. (Abstract 47-9-398.)

28. František Wolf: On generalized boundary values and the uniqueness of corresponding Dirichlet problems. (Abstract 47-9-407.)

29. R. J. Duffin and R. S. Pate: Generalized groups and the JordanHölder theorem. (Abstract 47-9-340.)

30. Morris Marden: The zeros of certain composite polynomials. (Abstract 47-9-345.)

31. H. H. Campaigne: An example of a cogroup. (Abstract 47-9337.)

32. D. C. Murdoch: Automorphisms and quasi-groups. Preliminary report. (Abstract 47-9-347.)

33. Rufus Oldenburger: The factorization of polynomials. (Abstract 47-9-349.)

34. D. G. Bourgin: Some properties of Banach spaces. (Abstract 479-369.)

35. F. B. Jones: Measure and other properties of a Hamel basis. (Abstract 47-9-386.)

36. R. S. Phillips: On weakly compact subsets of a Banach space. Preliminary report. (Abstract 47-9-399.)

37. M. M. Day: Reflexivity criteria for a Banach space. (Abstract 47-9-374.)

38. Herman Meyer: Polynomial approximations to functions defined on abstract spaces. (Abstract 47-9-395.) 
39. Bernard Friedman: Fourier coefficients of odd functions. (Abstract 47-9-380.)

40. R. J. Duffin and J. J. Eachus: A Paley-Wiener type expansion theorem. (Abstract 47-9-375.)

41. R. P. Boas: Generalized Laplace integrals. (Abstract 47-7-303.)

42. R. P. Agnew: Analytic extension by Hausdorff methods. (Abstract 47-9-363.)

43. J. H. Curtiss: Riemann sums and the fundamental polynomials of Lagrange interpolation. (Abstract 47-7-305.)

44. J. M. Earl: Polynomials of interpolation on an infinite interval. (Abstract 47-9-377.)

45. R. L. Moore: On continua with dendratomic subsets. (Abstract 47-11-488.)

46. J. M. Dobbie: A certain method in additive number theory. Preliminary report. (Abstract 47-9-360.)

47. R. D. James: On the sieve method of Viggo Brun. (Abstract 47-9361.)

48. A. T. Brauer: On the least quadratic non-residue. (Abstract 47-9357.)

49. Albert Whiteman: Sums connected with the partition function. (Abstract 47-7-300.)

50. Fritz Herzog: On an application of a theorem by Burnside. (Ab stract 47-9-341.)

51. Gordon Pall: An elementary alternative to Dirichlet's theorem. (Abstract 47-11-465.)

52. G. S. Young: On topologically flat subsets of certain spaces of $R$. L. Moore. (Abstract 47-9-452.)

53. O. G. Harrold: $A$ mapping characterization of Peano spaces. (Abstract 47-9-444.)

54. R. H. Fox: Homotopy type and deformation retraction. (Abstract 47-9-442.)

55. N. E. Steenrod: Topological methods for the construction of tensor functions. (Abstract 47-11-489.)

56. Max Dehn: On the mapping of closed surfaces. (Abstract 47-9440.)

57. A. W. Tucker: $A$ boundary-value theorem for harmonic tensors. (Abstract 47-9-449.)

58. Samuel Eilenberg and Saunders MacLane: Infinite cycles and homologies. (Abstract 47-11-487.)

59. Henry Wallman : Dimension for general spaces. (Abstract 47-11490.) 
60. R. P. Agnew and Mark Kac: On differences of elements of sets having positive Haar measure. (Abstract 47-9-365.)

61. P. R. Halmos and John von Neumann: Operator methods in classical mechanics. II. (Abstract 47-9-385.)

62. Shizuo Kakutani and Warren Ambrose: Structure and continuity of measurable flows (Abstract 47-9-389.)

63. Szolem Mandelbrojt: New proof of the conditions of quasianalyticity. (Abstract 47-9-393.)

64. J. W. T. Youngs: A generalized Lebesgue integral. (Abstract 479-409.)

65. Arthur Rosenthal: On differentiation of integrals and approximate continuity. (Abstract 47-9-401.)

66. R. B. Kershner: On the packing of convex regions in the plane. Preliminary report. (Abstract 47-9-390.)

67. A. D. Campbell: On the application of barycentric coordinates to lattice theory. (Abstract 47-9-338.)

68. A. A. Albert: Non-associative algebras. I. (Abstract 47-9-331.)

69. L. R. Wilcox: Complementation and modularity in lattices. (Abstract 47-9-356.)

70. Richard Brauer: On the indecomposable representations of algebras. (Abstract 47-9-334.)

71. R. M. Thrall: On symmetrized Kronecker powers and Lie representations of the full linear group. (Abstract 47-9-353.)

72. G. K. Kalisch: On Jordan algebras. (Abstract 47-9-344.)

73. Wilfred Kaplan: Topology of the two-body problem. (Abstract 479-412.)

74. Eric Reissner: On the equations of the stability theory of thin shells. (Abstract 47-9-415.)

75. Isaac Opatowski: On the theory of lethal irradiation of microörganisms. I. (Abstract 47-9-414.)

76. A. S. Householder: $A$ theory of steady-state activity in nervefiber networks. IV: $n$ circuits with a common synapse. (Abstract 47-9411.)

77. W. K. Feller: On the integral equation of the renewal theory. (Abstract 47-9-435-t.)

78. Hilda P. Geiringer: Some observations on analysis of variance theory. (Abstract 47-11-484-t.)

79. Raphaël Salem: On sets of multiplicity for trigonometrical series. (Abstract 47-9-402-t.)

80. T. F. Glass and Walter Leighton: On the convergence of continued fractions. (Abstract 47-9-384-t.) 
81. J. P. LaSalle: A characterization of topological spaces. (Abstract 47-9-447-t.)

82. A. D. Wallace: Regularly ordered systems of sets. (Abstract 47-9-450-t.)

83. Ralph Mansfield: Differential systems involving $k$-point boundary conditions. (Abstract 47-9-394-t.)

84. H. A. Simmons: Classes of maximum numbers associated with two symmetric equations in $n$ reciprocals. (Abstract 47-9-351-t.)

85. Stefan Bergman and D. C. Spencer: Some properties of pseudoconformal transformations in the neighborhood of boundary points. (Abstract 47-9-368-t.)

86. B. W. Jones: On an extension of a theorem of Witt. (Abstract 47-9-343-t.)

87. Alexander Weinstein: On the buckling of a rectangular clamped plate compressed in one direction. (Abstract 47-9-416-t.)

88. Edward Kasner and J. J. DeCicco: Geometry of dual-velocity systems. (Abstract 47-5-265-t.)

89. Edward Kasner and J. J. DeCicco: General differential geometry of second order differential elements. (Abstract 47-7-321-t.)

90. Edward Kasner and J. J. DeCicco: Conformal geometry of series of third order differential elements. (Abstract 47-7-320-t.)

91. Edward Kasner and J. J. DeCicco: Pseudo-conformal geometry: functions of two complex variables. (Abstract 47-9-424-t.)

92. J. J. DeCicco: Equilong geometry of series of collineal third order differential elements. (Abstract 47-7-319-t.)

93. E. N. Oberg: Notes on the approximation of a function by sums of orthonormal functions. Preliminary report. (Abstract 47-7-311-t.)

94. T. A. Botts: On convex sets in linear normed spaces. (Abstract 47-7-327-t.)

95. J. D. Mancill: On the solutions of a certain class of partial differential equations. (Abstract 47-7-310-t.)

96. A. W. Jones: On the characterization of groups whose lattices satisfy specified lattice identities. (Abstract 47-7-295-t.)

97. C. J. Everett: Vector spaces over rings. (Abstract 47-7-294-t.)

98. Nathaniel Coburn: Semi-analytic unitary subspaces of unitary spaces. (Abstract 47-9-419-t.)

99. Gordon Pall: Quaternions and sums of three squares. (Abstract 47-9-350-t.)

100. P. W. Carruth: Arithmetic of ordinals with applications to the theory of ordered abelian groups. (Abstract 47-9-339-t.)

101. Marston Morse and G. A. Hedlund: Manifolds without conjugate points. (Abstract 47-9-425-t.) 
102. E. A. Knobelauch: Extension of homeomorphisms on the torus and projective plane. (Abstract 47-9-445-t.)

103. J. D. Mancill: Multiple integral problems of the calculus of variations with prescribed transversality coefficients. (Abstract 47-9392-t.)

104. Louis Weisner: Roots of certain classes of polynomials. (Abstract 47-9-355-t.)

105. František Wolf: On the summability of trigonometrical integrals. (Abstract 47-9-408-t.)

106. Orrin Frink: Topology in lattices. (Abstract 47-9-443-t.)

107. M. M. Day: Ergodic theorems for abelian semi-groups. (Abstract 47-9-372-t.)

108. M. M. Day: Operations in Banach spaces. (Abstract 47-9373-t.)

109. H. L. Garabedian: Theorems relating to the Cesàro kernel transformation. (Abstract 47-9-382-t.)

110. H. L. Garabedian: A class of linear integral transformations. (Abstract 47-9-381-t.)

111. Deane Montgomery and Leo Zippin: A theorem on Lie groups. (Abstract 47-9-346-t.)

112. Garrett Birkhoff: Metric foundations of geometry. (Abstract 47-9-428-t.)

113. Olga Taussky and Ernest Best: $A$ class of groups. (Abstract 47-9-352-t.)

114. A. A. Albert: Division algebras over a function field. (Abstract 47-9-330-t.)

115. D. C. Spencer: A function-theoretic identity. (Abstract 47-9403-t.)

116. C. C. Camp: A convergence proof involving an inseparable multiple contour integral. (Abstract 47-9-371-t.)

117. S. A. Jennings: Central chains of ideals in an associative ring. (Abstract 47-9-342-t.)

118. R. P. Agnew: On Hurwitz-Silverman-Hausdorff methods of summability. (Abstract 47-9-364-t.)

119. R. H. Bruck and T. L. Wade: On a tensor algebra of Cramlet. (Abstract 47-9-336-t.)

120. T. L. Wade: Euclidean concomitants of the ternary cubic. (Abstract 47-9-354-t.)

121. R. H. Bruck: The number of absolute invariants of a tensor. (Abstract 47-9-335-t.)

122. Mark Kac: Convergence and divergence of non-harmonic gap series. (Abstract 47-9-387-t.) 
123. Shizuo Kakutani: A class of examples of mixing flows. (Abstract 47-9-388-t.)

124. E. L. Buell: On the distribution of plane stress in a semi-infinite plate with partially stiffened edge. Preliminary report. (Abstract 47-9-410-t.)

125. G. S. Young: On the outer boundaries of certain connected domains. (Abstract 47-9-451-t.)

126. Abe Gelbart: On some properties of mapping functions. (Abstract 47-9-383-t.)

127. M. G. Moore: On functions satisfying two functional equations. (Abstract 47-9-396-t.)

128. Richard Brauer: Investigations on group characters. (Abstract 47-9-333-t.)

129. Brockway McMillan: Absolutely monotone functions. Preliminary report. (Abstract 47-11-471-t.)

130. Ivan Niven: Quadratic diophantine equations in the rational and quadratic fields. (Abstract 47-9-362-t.)

131. Ivan Niven: The mth roots of a quaternion. (Abstract 47-9348-t.)

132. L. R. Wilcox: Extensions of semi-modular lattices. II. (Abstract 47-11-461-t.)

133. Leonard Carlitz: Note on generalized Bernoulli and Euler numbers. (Abstract 47-9-358-t.)

134. Leonard Carlitz: The coefficients of the reciprocal of a series. (Abstract 47-9-359-t.)

135. E. H. Nicholson: On the degree of approximation in some convergence theorems concerning derivatives of the mapping function in conformal mapping. (Abstract 47-9-397-t.)

136. S. M. Ulam and D. H. Hyers: On approximate isometries. Preliminary report. (Abstract 47-9-427-t.)

137. S. M. Ulam: On measures for subsets of sets of measure zero. (Abstract 47-9-405-t.)

138. E. F. Beckenbach: Vector formulations of Morera's theorem. (Abstract 47-9-367-t.)

139. Paul Erdös and Gabor Szegö: On a problem of I. Schur. (Abstract 47-9-378-t.)

140. Reinhold Baer: Automorphism rings of primary abelian operator groups. (Abstract 47-9-332-t.)

141. H. S. Vandiver: An arithmetical theory of Bernoulli numbers. (Abstract 47-11-466-t.) 